Nihal Sirakaya Erese $\odot$ Nurgül Yurtseven $\odot$ Emine Hekim Yılmaz $\odot$ Okan Yurdakök ๑ Suna Yaka (1)

\title{
Organ Dysfunction and Mortality Relationship in Patients with Extracorporeal Membrane Oxygenation After Pediatric Cardiac Surgery
}

Etik Kurul Onayı: S.B. Dr. Siyami Ersek Göğüs Kalp ve Damar Cerrahisi Eğitim ve Araştırma Hastanesi Yerel Etik Kurulu'ndan onay alınmıştır (19.06.2017 - 3910).

Çıkar çatışması: Çıkar çatışması olmadığını bildirmişlerdir.

Finansal destek: Bu çalışma, herhangi bir fon tarafından desteklenmemiștir.

Hasta onami: Hasta ve hasta yakınlarından aydinlatımıs onam alınmıştir.
Ethics Committee Approval: S.B. Dr. The approval was obtained from the Local Ethics Committee of Siyami Ersek Thoracic and Cardiovascular Surgery Training and Research Hospital (19.06.2017 - 3910)

Conflict of interest: The authors reported no conflict of interest.

Funding: This work was not supported by any funding.

Informed consent: Informed consent: Informed consent was obtained from the patient and relatives.

Cite as: Sirakaya Erese N, Yurtseven N, Yılmaz EH, Yurdakök O, Yaka S. Pediyatrik kardiyak cerrahi sonrası ekstrakorporeal membran oksijenasyonu uygulanan hastalarda organ disfonksiyonu ve mortalite ilișkisi. GKDA Derg. 2020;26(3):157-64

öz

Amaç: Konjenital kalp hastalıklarında kompleks kardiyak cerrahi ameliyatlarının artısılyla birlikte, ekstrakorporeal membran oksijenasyonu (ECMO) gibi mekanik destek cihazlarının uygulaması artmıştır. ECMO teknikleri ve yöntemlerindeki önemli gelișmelere rağmen, prognoz hâlâ kötüdür. Bu çalıșmanın amacı, pediyatrik kalp cerrahisi sonrası venö-arteriyel (VA) ECMO takılan hastaları değerlendirmek ve bu hastalarda organ disfonksiyonu ile mortalite arasındaki ilişkiyi göstermektir.

Yöntem: Kliniğimizde VA-ECMO takılan ve 48 saatten daha uzun süre takip edilen 63 hasta retrospektif olarak çalışmaya alındı ve iki grup oluşturuldu. Grup 1: 30 gün içinde mortal seyreden hastalar (n: 47), Grup 2: Yasayan hastalar (n: 16). Hastaların demografik verileri ile birlikte, ECMO yerlestirme zamani, kreatinin, BUN (kan üre nitrojen), ALT (alanin aminotransferaz), AST (aspartat aminotransferaz), bilirubin, albumin ve platelet düzeyleri kaydedildi.

Bulgular: Çalışma grubumuzda 36 hasta (\%57.1) ECMO'dan ayrılırken, bu hastalardan 16'sı (16/63, \%25.4) taburcu oldu. Toplamda 47 hasta (47/63, \%74.6) eksitus oldu. Grup 1'de univentriküler tamir yapılan (26/47, \%55.31) hasta sayısı Grup 2'ye göre daha yüksek 5 (\%31.25) olmakla birlikte, bu fark anlamlı bulunmadi (p>0.05). Grup 1'de 27 hastaya (\%57.44\%), Grup 2'de ise 4 hastaya (\%31.25) postoperatif ECMO yerleştirilmiş olup, bu fark istatistiksel olarak anlamlı bulundu $(p<0.02)$. Mortal seyreden Grup 1 hastalarında kreatinin, BUN, ALT, AST yüksek iken, albümin ve platelet değerleri Grup 2'ye göre düşük bulundu $(p<0.05)$.

Sonuç: Organ disfonksiyon parametrelerinin mortaliteyi göstermede etkili olduğu ve ECMO'nun postoperatif olarak yerleștirildiği hastalarda mortalitenin yüksek bulunduğu belirlenmiștir.

Anahtar kelimeler: ekstrakorporeal membran oksijenasyon, pediyatrik kardiyak cerrahi, mortalite

ABSTRACT

Objective: TThe application of mechanical support devices such as extracorporeal membrane oxygenatior (ECMO) has increased with the increase in complex cardiac surgery operations in congenital heart diseases. Despite significant advances in ECMO techniques and methods, the prognosis is still poor. The aim of this study is to show the relationship between organ dysfunction and mortality in patients with veno-arterial (VA) ECMO after pediatric cardiac surgery.

Method: Sixty-three patients in the pediatric cardiac ICU who had VA-ECMO and followed up up to 48 hours in our clinic, were retrospectively included in the study and two groups were formed as follows: Group 1: Patients exited within 30 days (n: 47), Group 2: Survived patients (n: 16). Along with the demographic data of the patients, ECMO placement time, creatinine, BUN (blood urea nitrogen), ALT (alanine aminotransferase), AST (aspartate aminotransferase), bilirubin, albumin and platelet counts were recorded.

Results: While 36 patients (57.1\%) left ECMO in our study group, 16 of these patients (16/63,25.4\%) were discharged. A total of 47 patients $(47 / 63,74.6 \%)$ died. Although the number of patients who underwent univentricular repair $(26 / 47,55.31 \%)$ in Group 1 was higher $(n=5: 31.25 \%)$ than Group 2, this difference was not significant ( $p>0.05$ ). Postoperative ECMO was implanted in 27 patients (57.44\%) in Group 1 and 4 patients $(31.25 \%)$ in Group 2, and this difference was statistically significant $(p<0.02)$. While levels of creatinine, BUN, ALT, AST were higher in Group 1 patients who had higher mortality rates, albumin and platelet values were lower than Group $2(p<0.05)$.

Conclusion: It has been determined that organ dysfunction parameters were found to be effective in showing mortality, mortality rates were higher among patients in whom ECMO was placed postoperatively.

Keywords: extracorporeal membrane oxygenation, pediatric cardiac surgery, mortality
Received/Geliş: 20.07 .2020

Accepted/Kabul: 14.08.2020

Published Online/Online yayın: 21.09.2020

Nurgül Yurtseven S.B.Ü. Dr. Siyamï Ersek Göğüs Kalp ve Damar Cerrahïsi Anestezi ve Reanimasyon Kliniği İstanbul, Türkiye

nurgulyurtseven@hotmail.com ORCID: 0000-0001-9991-2859

N. S. Erese 0000-0002-9577-8901 S. Yaka 0000-0001-7649-8421 S.B.Ü. Dr. Siyamï Ersek Göğüs Kalp ve Damar Cerrahïsï Anestezi ve Reanimasyon Kliniği İstanbul, Türkiye

E. H. Yilmaz 0000-0001-5333-4336 S.B.Ü. Dr. SiyamïErsek Göğüs Kalp ve Damar Cerrahïsi Pediyatrik Kardiyoloji Kliniği istanbul, Türkiye

O. Yurdakök 0000-0003-1296-4061 S.B.Ü. Dr. Siyamï Ersek Gögüs Kalp ve Damar Cerrahïsi Pediyatric Kardiyovasküler Cerrahi Kliniği Istanbul, Türkiye

(C) Telif hakkı Göğüs Kalp Damar Anestezi ve Yoğun Bakım Derneği'ne aittir. Logos Tıp Yayıncılık tarafindan yayınlanmaktadır. Bu dergide yayınlanan bütün makaleler Creative Commons Atf-Gayri Ticari 4.0 Uluslararası Lisansı ile lisanslanmıştr. 


\section{Giriş}

Konjenital kalp cerrahisi sonrası ECMO kullanımı, geleneksel tedavilere yanıt vermeyen, ciddi fakat geri döndürülebilir kalp ya da solunum yetmezliği olan hastalarda, son yıllarda giderek artmaktadır [1]. VA-ECMO'nun endikasyonları, preoperatif veya postoperatif uygulanmasına göre değişiklik gösterir. Özellikle hipoksi ve pulmoner hipertansiyonu olan hastalarda ameliyat öncesi, postoperatif dönemde, kardiyopulmoner baypastan ayrılamama, düşük kalp debisi veya kardiyak arrest durumlarında kullanılmaktadır ${ }^{[2-4]}$.

Kompleks kalp cerrahisi ameliyatlarının kendisinin yaratacağı risklere ek olarak ECMO uygulamalarında; trombositopeni, kanama, tromboemboli, infeksiyon, organ yetersizliği ve mortalitede artış gibi ciddi komplikasyonlar görülebilmektedir ${ }^{[5]}$. Bu grup hastalarda mortalite ve morbiditenin en aza indirilebilmesi için izlem oldukça önemlidir ${ }^{[6-8]}$.

Bu çalışmanın amacı, kliniğimizde ECMO takılan hastaları değerlendirmek ve izlemde kullanılan organ disfonksiyon parametrelerinin, 30 günlük mortaliteyi öngörmedeki yerini belirlemektir.

\section{GEREÇ ve YÖNTEM}

Hastanemiz Tıpta Uzmanlık ve Eğitim Kurulu onayı sonrası (19.06.2017-3910), kliniğimizde Ocak 2015 Haziran 2017 arasında pediyatrik kardiyovasküler cerrahi yoğun bakım ünitesinde izlenen ve kardiyak nedenlerle VA-ECMO'ya bağlanan 63 hasta retrospektif olarak incelendi. Hastalar mortaliteye göre 2 gruba ayrıldı: Grup 1: 30 gün içinde mortal seyreden hastalar (n:47), Grup 2: Yaşayan hastalar (n:16).

Hastaların organ fonksiyonlarını gösteren tüm laboratuvar verileri ile, yoğun bakım ve hastane yatış süreleri, veri tabanı sistemi ile geriye dönük olarak kaydedildi. Hastaların yaş, boy, ağırlık, kalp cerrahi geçirenlerde kardiyopulmoner baypas (KPB) ve krosklemp(KK) süreleri, ECMO süreleri perfüzyon kayıtla- rından elde edildi.

Çalışmadaki hastalara ECMO, santral yol ile sağ atrium ve asendan aorta kullanılarak takıldı. Kliniğimizde, Macquet firmasının sentrifugal tipte pompa özelliğine sahip cihaz kullanıldı. ECMO akımı $36.5^{\circ} \mathrm{C}^{\prime}$ de, 100 $-150 \mathrm{ml} / \mathrm{kg}$ olacak şekilde ayarlandı. Antikoagülasyon için heparin infüzyon dozu, aktive edilmiş parsiyel tromboplastin zamanı (aPTT) 60-80 aralığında koruyabilecek şekilde için titre edildi.

Organ fonksiyon belirteçleri olarak:

1. Böbrek fonksiyonu: Kreatinin $(\mathrm{mg} / \mathrm{dL})$, BUN $(\mathrm{mg} / \mathrm{dL})$, renal replasman tedavi desteği

2. Karaciğer fonksiyonu: AST (IU/L), ALT (IU/L), Total bilirubin (TB) ve direkt bilirubin (DB) $(\mathrm{mg} / \mathrm{dL})$, albumin $(\mathrm{g} / \mathrm{dL})$

3. Koagülasyon fonksiyonu: Platelet $\left(10^{3} / \mu \mathrm{L}\right)$

$B u$ değerler 1. gün (T1), 2. gün (T2), 4. gün (T3), 5. Gün (T4), ECMO'dan ayrılma günü (Tson) ile en düşük değerler (Tmin) ve en yüksek değerler (Tmax) olarak kaydedildi.

\section{Verilerin İstatistiksel Analizi}

Çalışmada elde edilen bulgular değerlendirilirken, istatistiksel analizler için SPSS 24.0 ístatistik paket programı kullanıldı. Çalışma verileri değerlendirilirken tanımlayıcı istatistiksel metotların (Frekans, Yüzde, Ortalama, Standart sapma) yanı sıra normal dağılımın incelenmesi için Kolmogorov-Smirnov dağıIım testi kullanıldı. Parametrelerin gruplararası karşılaştırmalarında Mann Whitney $U$ testi, 2 değişkenli gruplar için ise Fisher Exact test kullanıldı. Sonuçlar \% 95 güven aralığında, $p<0.05$ anlamlılık düzeyinde değerlendirildi.

\section{BULGULAR}

Pediyatrik kardiyak yoğun bakım ünitesinde takip edilen ortalama yaşları $20.163 \pm 42.19$ ay, ortalama ağırlıkları $7.833 \pm 8.905 \mathrm{~kg}$ olan 63 hastaya, kardiyopulmoner baypastan ayrılamama (31/63, \%49.2), postoperatif kardiyak yetmezlik $(28 / 63, \% 44.4)$, pos- 
N. S. Erese ve ark., Pediyatrik Kardiyak Cerrahi Sonrası Ekstrakorporeal Membran Oksijenasyonu Uygulanan Hastalarda Organ Disfonksiyonu ve Mortalite İlişkisi

toperatif aritmi (1/63,\%1.58), kardiyopulmoner resusitasyon (2/63, \%3.17) ve dilate kardiyomiyopati $(1 / 63, \% 1.58)$ nedeniyle VA-ECMO takıldı (Tablo 1$)$.

Tablo 1. ECMO yerleştirilen hastaların özellikleri (ortalamatstandart sapma).
Yaş (ay)

Ağırlık (kg)

Boy $(\mathrm{cm})$

BSA $\left(\mathrm{m}^{2}\right)$

Baypas (dk.)

Kros klemp (dk.)

ECMO süresi (saat)

\begin{tabular}{lc}
\hline ECMO takılma nedenleri & Sayı (\%) \\
\hline KPB tan ayrılamama & $31(\% 49.2)$ \\
Post operatif kardiyak yetmezlik & $28(\% 44.4)$ \\
Postoperatif aritmi & $1(\% 1.58)$ \\
Kardiyopulmoner resusitasyon & $2(\% 3.17)$ \\
Dilate kardiyomiyopati & $1(\% 1.58)$ \\
\hline
\end{tabular}

Grupların demografik verileri Tablo 2'de gösterilmiştir. Grup 1 hastalarında yaş, Grup 2'ye göre daha düşük, ECMO süresi ise anlamlı olarak yüksek bulun$d u(p<0.05)$. Grup 1'de 26 (\%55.31) hastaya univentriküler cerrahi uygulanırken, Grup 2'de 5 (\%31.25) hastaya uygulandı ve bu fark istatistiksel olarak anlamlı bulunmadı $(p>0.05)$. Grup 1 hastalarının 20'sine (\%42.56) peroperatif dönemde, 27'sine (\%57.44) postoperatif dönemde ECMO yerleştirilirken bu oranlar Grup 2'de peroperatif dönem için 12 (\%68.75) postoperatif dönem için (\%31.25) olarak

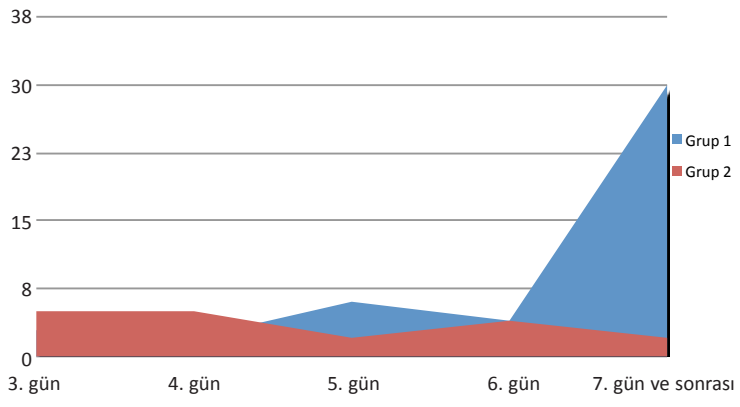

Şekil 1. Grupların ECMO kalış sürelerine göre karşılaşturılmaları.

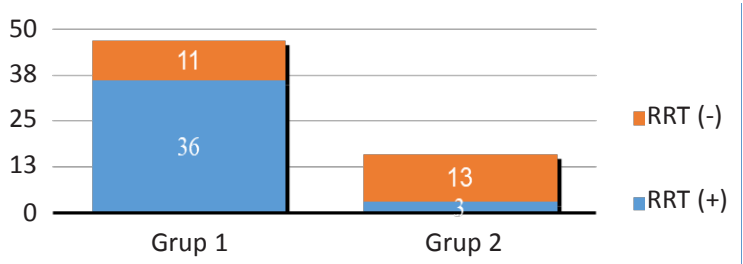

Şekil 2. Grupların RRT açısından karşılaştırılması.

\section{Tablo 2. Grupların özellikleri.}

belirlendi ve bu fark istatistiksel olarak anlamlı bulun$d u(p<0.02)$. Grup 1'de 5. günde mortalitenin arttığı ve ECMO'da kalış süresi uzadıkça mortalitenin daha yüksek seyrettiği belirlendi (Şekil 1). Hastaların 27'si (\%42.85) ECMO'dan ayrilamazken, 36 hasta ECMO'dan ayrıldı (\%57.15) ve bu hastaların 16'sı (16/63, \%25.4) taburcu oldu.

Grupların organ disfonksiyon parametreleri Tablo 3'de gösterilmiştir. Grup 1'de T1, T2, T3, Tmin ve Tmax zamanlarında kreatinin ölçümleri, Tson, Tmin

\begin{tabular}{lccc} 
& Grup (n: 47) & Grup 2 (n: 16) & p \\
\hline Yaş (ay) & $18.93 \pm 39.52$ & $23.79 \pm 50.50$ & 0.047 \\
Ağırlık (kg) & $7.55 \pm 8.84$ & $8.68 \pm 9.34$ & 0.090 \\
Boy (cm) & $65.43 \pm 27.03$ & $71.75 \pm 29.63$ & 0.133 \\
BSA (m²) & $0.35 \pm 0,27$ & $0.40 \pm 0.30$ & 0.553 \\
Baypas (dk.) & $222.95 \pm 110.76$ & $217.44 \pm 125.31$ & 0.635 \\
Kros klemp (dk.) & $113.97 \pm 68.37$ & $108.94 \pm 74.13$ & 0.408 \\
ECMO süresi (saat) & $237.94 \pm 123.79$ & $120.00 \pm 51.85$ & $* 000$ \\
Univentriküler cerrahi (\%) & $26(\% 55.31)$ & $5(\% 31.25)$ & 0.07 \\
ECMO takılma zamanı (n\%) & & $12(\% 68.75)$ & $* 0.02$ \\
$\quad$ Peroperatif ECMO & $20(\% 42.56)$ & $4(\% 31.25)$ & \\
Postoperatif ECMO & $27(\% 57.44)$ & & \\
\hline
\end{tabular}

$* P<0.05$ 
Tablo 3. Grupların organ disfonksiyon parametrelerinin karşılaştırılması. Gruplar arası karşılaştırma $\left({ }^{*} p<0.05\right)$.

\begin{tabular}{|c|c|c|c|c|c|c|c|}
\hline & T1 & $\mathrm{T} 2$ & T3 & T4 & Tson & Tmin & Tmax \\
\hline $\begin{array}{l}\text { Kreatinin }(\mathrm{mg} / \mathrm{dL}) \\
\text { Grup } 1\end{array}$ & $0.87 \pm 0.5 *$ & $0.98 \pm 0.7 *$ & $0.96 \pm 0.5^{*}$ & $0.9 \pm 0.5$ & $0.77 \pm 0.4$ & $0.66 \pm 0.5^{*}$ & $1.3 \pm 0.8 *$ \\
\hline Grup 2 & $0.64 \pm 0.3$ & $0.73 \pm 0.7$ & $0.6 \pm 0.3$ & $0,63 \pm 0.4$ & $0.52 \pm 0.2$ & $0.33 \pm 0.06$ & $0.71 \pm 0.5$ \\
\hline $\begin{array}{l}\text { BUN (mg/dL) } \\
\text { Grup } 1\end{array}$ & $21.1 \pm 15.9$ & $26.34 \pm 17.9$ & $32.8 \pm 20.3$ & $33.24 \pm 18.5$ & $47 \pm 38.2 *$ & $29.36 \pm 19.9 *$ & $78 \pm 28.5 *$ \\
\hline Grup 2 & $24.79 \pm 19.2$ & $25.07 \pm 17.4$ & $35.55 \pm 27.4$ & $29.25 \pm 21.1$ & $23.2 \pm 15.6$ & $8.31 \pm 2.7$ & $36.25 \pm 16.1$ \\
\hline $\begin{array}{l}\text { Albumin (g/dL) } \\
\text { Grup } 1\end{array}$ & $3.52 \pm 3.7$ & $3.07 \pm 3.1^{*}$ & $2.64 \pm 0.5$ & $2.77 \pm 0.7$ & $2.54 \pm 0.6^{*}$ & $2.03 \pm 0.7^{*}$ & $3.01 \pm 0.3^{*}$ \\
\hline Grup 2 & $2.92 \pm 0.4$ & $3.15 \pm 0.4$ & $2.82 \pm 0.3$ & $2.85 \pm 0.4$ & $4.56 \pm 5.5$ & $3.2 \pm 1.6$ & $5.59 \pm 5.7$ \\
\hline $\begin{array}{l}\text { TB (mg/dL) } \\
\text { Grup } 1\end{array}$ & $2.98 \pm 3.5$ & $4.86 \pm 3.2$ & $8.02 \pm 6.5^{*}$ & $7.98 \pm 5.5$ & $15.62 \pm 15.8$ & $3.25 \pm 3.6$ & $10.22 \pm 12.4$ \\
\hline Grup 2 & $2.76 \pm 2.5$ & $4.01 \pm 2.8$ & $1.41 \pm 0.7$ & $0.32 \pm 0.0$ & $3.02 \pm 2.1$ & $0.74 \pm 0.5$ & $2.75 \pm 4.1$ \\
\hline $\begin{array}{l}\text { DB (mg/dL) } \\
\text { Grup } 1\end{array}$ & $1.4 \pm 2.3$ & $1.28 \pm 1.8$ & $3.52 \pm 3.6$ & $2.05 \pm 2.0$ & $8.04 \pm 8.6^{*}$ & $2.5 \pm 3.09 *$ & $6.43 \pm 7.2^{*}$ \\
\hline Grup 2 & $0.99 \pm 1$ & $0.98 \pm 1$ & $0.74 \pm 0.1$ & $0.5 \pm 0.2$ & $0.53 \pm 0.1$ & $0.28 \pm 0.1$ & $1.39 \pm 2.8$ \\
\hline $\begin{array}{l}\text { AST (IU/L) } \\
\text { Grup } 1\end{array}$ & $1027.3 \pm 2811$ & $998.59 \pm 2506$ & $654.76 \pm 978 *$ & $303.32 \pm 418^{*}$ & $363.78 \pm 684 *$ & $49.64 \pm 40$ & $371.93 \pm 549$ \\
\hline Grup 2 & $594.57 \pm 1221$ & $905.33 \pm 2089$ & $141 \pm 188$ & $76.75 \pm 59$ & $80.56 \pm 82$ & $14.25 \pm 5$ & $209.31 \pm 397$ \\
\hline $\begin{array}{l}\text { ALT } \\
\text { Grup } 1(\mathrm{IU} / \mathrm{L})\end{array}$ & $275.2 \pm 736$ & $344.11 \pm 749$ & $237,57 \pm 440 *$ & $135.73 \pm 272$ & $136.7 \pm 296$ & $42 \pm 52$ & $138.93 \pm 187$ \\
\hline Grup 2 & $272.14 \pm 587$ & $371 \pm 812$ & $131,73 \pm 244$ & $133.38 \pm 277$ & $96.94 \pm 205$ & $9.56 \pm 4$ & $130.19 \pm 199$ \\
\hline $\begin{array}{l}\text { Platelet }\left(10^{3} / \mu \mathrm{L}\right) \\
\text { Grup } 1\end{array}$ & $117.49 \pm 77$ & $116.02 \pm 79$ & $75,96 \pm 61$ & $70.67 \pm 50$ & $94.7 \pm 71$ & $45.79 \pm 47 *$ & $180.72 \pm 129 *$ \\
\hline Grup 2 & $130.16 \pm 82$ & $141.28 \pm 90$ & $61,03 \pm 21$ & $74.48 \pm 21$ & $84.31 \pm 54$ & $103.16 \pm 87$ & $476.63 \pm 157$ \\
\hline
\end{tabular}

ve Tmax zamanlarında BUN ölçümleri Grup 2 ile karşılaştırıldığında anlamlı olarak yüksek bulundu $(p<0.05)$. Bu hastalara renal replasman tedavi uygulama gereksinimi de, daha fazlaydı $(p<00001)$ (Şekil 2). Benzer şekilde Grup 1'de T2, Tson, Tmin ve Tmax zamanlarında albümin düzeyleri daha düşük bulunurken, T3 zamanında total bilirubin düzeyleri, Tson, Tmin ve Tmax zamanlarında da direkt bilirubin düzeyleri anlamlı olarak yüksekti $(p<0.05)$. Karaciğer fonksiyon parametrelerinden AST ölçümleri Grup 1'de T3, T4 ve Tson zamanlarında, ALT ölçümleri Tmin zamanında anlamlı ola- rak yüksek bulundu $(p<0.05)$. Platelet düzeyleri ise Tmin ve Tmax zamanlarında Grup 2'ye göre anlamlı olarak düşüktü.

\section{TARTIŞMA}

Konjenital kalp cerrahisi sonrası ECMO takılan hastaları retrospektif olarak değerlendirdiğimiz çalışmamızda, organ disfonksiyon parametreleri ile mortalite arasında yakın ilişki olduğu gösterilmiş ve özellikle peroperatif dönemde uygulanan ECMO'da mortalitenin daha az olduğu belirlenmiştir. 
N. S. Erese ve ark., Pediyatrik Kardiyak Cerrahi Sonrası Ekstrakorporeal Membran Oksijenasyonu Uygulanan Hastalarda Organ Disfonksiyonu ve Mortalite İlişkisi

Kardiyak arrest, ciddi kardiyojenik şok veya kardiyopulmoner baypastan ayrılamayıp VA-ECMO takılan hastalarda, yaşayan hasta oranı \%20-30 aralığında iken, Extracorporeal Life Support Organization (ELSO) verilerine göre, yenidoğan ve pediyatrik yaş grubunda kardiyak amaçlı kullanılan ECMO'lardan ayrılma oranı \%65-\%69 iken, hastaneden çıkma oranı \%41 -\%51 olarak bildirilmiştir ${ }^{[9-11]}$. Çalışmamızda, ECMO'dan ayrılma oranı \%57.1 iken, hastaneden çıkma oranı ise \%25.4 olarak belirlenmiştir. Hastaneden çıkma oranının düşük olmasının nedeninin, çalışmanın yapıldığı zaman aralığı itibariyle ECMO ile ilgili tecrübenin az olmasından kaynaklandığını düşünüyoruz. Yapılan çalışmalarda, özellikle univentriküler cerrahi sonrası ECMO takılan hastalarda mortalite oranı, biventriküler cerrahi yapılan hastalara göre daha yüksek bulunmuştur ${ }^{[12]}$. Dohain ve ark. ${ }^{[13]}$ univentriküler cerrahide $\% 83.33$ varan bir mortalite yüksekliği bildirmiştir. Çalışmamızda her ne kadar istatistiksel olarak anlamlı fark bulunamasa da, Grup 2 hastalarında, univentriküler cerrahi yapılan hasta sayısının daha az olması, biventriküler tamir yapılan hastaların daha yüksek sağ kalım oranına sahip olma eğiliminde olduğunu düşündürmektedir.

Pediyatrik hastalarda, yaş ve kilonun fazla olması, hasta taburculuğuna olumlu yönde etki eden faktörlerdendir ${ }^{[14]}$. Çalışmamızda da, Grup 1'de yaş anlamIı olarak düşük iken, kilo Grup 2'ye göre daha az olmakla birlikte, istatistiksel olarak bir anlamlılık bulunamamıştır.

Black ve ark.'nın ${ }^{[15]}$ çalışmasında, 6 günden uzun süren ECMO takılı olan hastalarda yaşayan olmadığını belirtmiştir. Smith ve ark. ${ }^{[11]}$ tarafından ELSO verileri taranarak yapılan çalışmada, 4. günde sağkalımın arttığı, ECMO süresi uzadıkça sağkalımın azaldığı gösterilmiştir. Çalışmamızda da Grup 1'de özellikle 5. günde mortalitenin arttığı ve bu hastalarda ECMO'ya bağlı kalış süresinin Grup 2'ye göre anlamlı yüksek olduğu belirlenmiştir.

KPB ile akut böbrek yetmezliği arasındaki ilişki hakkında fazla sayıda araştırma olmasına rağmen, ECMO ve akut böbrek hasarı arasındaki ilişkiyi gösteren mekanik ve klinik veri yetersizdir ${ }^{[16]}$. Akut böbrek hasarı ECMO'daki hastalarda \%70-85 gibi yüksek bir oranda gözlenmekte ve \%80' kadar çıkan mortalite ile ilişkilidir [17-19]. ECMO'da gözlenen akut böbrek yetmezliğinin patofizyolojisinin multifaktöriyel, kompleks ve zaman bağımlı olduğu açıktır. ECMO desteği uzadıkça da, akut böbrek hasarının gelişme riski artmaktadır. Şu anki klinik uygulamalarda böbrek hasarı belirlenmesi için, idrar çıkısıı ve biyokimyasal değerler (serum kreatinin, kan /idrar nitrojeni, kan/idrar elektrolitleri) kullanılmaktadır [20]. Çalışmamızda, mortal seyreden Grup 1 hastalarında T1, T2, T3, Tmin ve Tmax zamanlarındaki kreatinin, Tson, Tmin ve Tmax zamanlarında BUN ölçümlerinin Grup 2'ye göre yüksek olduğu ve bu grubun daha fazla renalreplasman tedaviye gereksinim duyduğu belirlendi $(p<0.05)$.

Hipoalbümineminin ortaya çıkışında rol oynayan mekanizmalar multifaktöryel olup, sentez süreçlerini içeren, katabolizma ve amino asit arzı, su tutma ve endotel geçirgenliğinin değişimiyle ekstravasküler alana kayıp şeklindedir ${ }^{[21,22]}$. Bir akut faz reaktanı olan ve karaciğerde sentezlenen albüminin, kısa dönem mortaliteyle ve uzun hastane yatışı ve komplikasyonlarla ilişkisi gösterilmiştir ${ }^{[23,24]}$. Leite ve arkadaşları hipoalbumineminin konjenital kalp hastalığı olanlarda yaygın olduğunu ve bunun kalp cerrahisinin sonuçlarıyla ilişkili olduğunu göstermiştir [25]. Hasta grubumuzda yine Grup 1 hastalarında albümin düzeyleri daha düşük seyretmiştir.

Genel olarak, erken hepatik disfonksiyon özellikle kalp yetmezliği olan yoğun bakım hastalarında kötü prognoz için bağımsız bir risk faktörüdür. Karaciğer fonksiyon testlerindeki bilirubin, ALT, ALP VE GGT olmak üzere ufak artışların bile, akut hastalarda kötü prognozla ilişkisi vardır. ECMO'lu hastalarda, karaciğer yetmezliği yaygın ve ciddi bir komplikasyondur [26,27]. Hasta populasyonundaki ciddi kardiyovasküler hastalıklar tek başına karaciğer fonksiyonlarını etkileyebilir. Dahası, hepatik sistemdeki bozulmalar primer olarak karaciğerin kendi hastalığından değil, şiddetli 
bir hastalığın sonucu ve yaygın stres yanıtının da bir sonucu olabilir ${ }^{[27]}$. ECMO tedavisinde karaciğer perfüzyonu, pompa akımı ve pulsatil akım yokluğu, ECMO sonrası değişen vasopresör dozları ve hava veya trombüs embolizasyonu ile etkilenebilir [28]. Çalışmamızda, AST ve ALT düzeyleri yaşayan hasta grubunda anlamlı olarak daha düşük bulunmuştur. Roth ve ark. [28], kardiyovasküler cerrahi sonrası VA-ECMO'ya bağlanan hastalarda, 30 günlük mortaliteyi göstermede alkalen fosfataz ve total bilirubinin en güçlü prediktör olduğunu bildirmişlerdir. Çalışmada, kardiyovasküler cerrahiyi takiben ECMO takılan hastaların preoperatif olarak karaciğer testlerinin mortalite tahminindeki etkisi gösterilmiştir. Kaestner ve ark.'nın ${ }^{[29]}$ çalışmasında ise, bilirubin, laktat ve $\mathrm{N}$-terminal pro-brain natriüretik peptid ECMO sırasındaki mortalite ile ilişkilendirilmiştir. Ancak, bu çalışmada bilirubin değerleri yalnızca en yüksek olduğu dönemde çalışılmıştır. Çalışmamızda da, total ve direkt bilirubin değerleri, Grup 1 hastalarında istatistiksel olarak anlamlı yüksek bulunmuştur $(p<0.05)$.

Kanama ECMO hastalarındaki mortalitenin önde gelen nedenidir. Çoğunlukla, ECMO kanülasyon bölgeleri ya da vücuttaki diğer cerrahi alanlarda gözlenir. Hemostaz kompleks bir süreçtir ve ECMO'lu hastalarda yeterli hemostaz sürecini bozan bir çok hücresel etkileşimler vardır ${ }^{[30]}$. Trombositopeni, yoğun bakım hastalarında sık görülür ve ciddi trombositopeni, artmış kanama ve mortalite ile ilişkilidir. Trombositopenisi olan ECMO'lu hastaların ve trombosit düşüklüğünün derecesiyle ilgili oranlar hakkında veriler eksiktir. ECMO'lu hastalarda kanama riskinin arttıran trombosit sayısı seviyesi bilinmemektedir ${ }^{[31]}$. Çalışmamızda, yaşayan Grup 2 hastalarındaki platelet sayısının, ölen hasta grubuna göre anlamlı olarak yüksek olduğu bulunmuştur $(p<0.05)$.

Gupta ve ark. ${ }^{[32]}$ yapmış oldukları çalışmalarında, kardiyak cerrahi sonrası ile ECMO' nun başlangıcına kadar geçen sürenin uzunluğu ile moratalite arasında bir ilişki bulamamışlar, ancak bu sürenin uzamasının
ECMO'dan ayrılma, ventilasyon süresi, yoğun bakım ve hastanede kalma süresini hergün için, \%1-3 oranında arttırdığını belirtmişlerdir. Alsoufi ve ark. ${ }^{[33]}$ ise, univentriküler cerrahi yapılan hastalarda ECMO mortalitesinin yüksek olduğunu ve özellikle organ yetmezliği oluşmadan yerleştirilen ECMO'nun mortaliteyi etkilediğini belirtmişlerdir. Çalışmamızda bu çalışmaya benzer şekilde, mortal seyreden Grup 1'de $\% 57.44$ (27/47) hastaya postoperatif dönemde ECMO takılırken, bu oran Grup 2'de \% 31.25 (11/16)'dir $(p<0.02)$. Hastaların kardiyovasküler stabilitesinin bozulmadan elektif şartlarda yerleştirilen ECMO'nun mortalite üzerine olumlu etkisi olduğu düşüncesindeyiz. Bu nedenle, hastaların olabildiğince erken dönemde ECMO desteğine alınmasımortalitenin azalmasına katkıda bulunacaktır.

Sonuç olarak, ECMO mortalitesi yüksek bir destekleyici tedavi sistemidir. Kliniğimizde özellikle konjenital kalp cerrahisinde uygulanım sıklığının ve klinik deneyiminin artmaya başladığı kesitsel bir süreci alan çalışmamızda, organ disfonksiyon parametreleri mortalite ile ilişkilendirilirken, özellikle planlı olarak peroperatif dönemde takılan ECMO'nun mortalitede azalmaya yol açtığı belirlenmiştir.

\section{KAYNAKLAR}

1. Sasaki T, Asou T, Takeda Y, Onakatomi Y, Tominaga T, Yamamoto Y. Extracorporeal life support after cardiac surgery in children: Outcomes from a single institution. Artif Organs. 2014 Jan; 38(1):34-40. https://doi.org/10.1111/aor.12191

2. Trittenwein G, Furst G, Golej J, Frenzel K, Burda G, Hermon M. et al. Preoperative ECMO in congenital cyanotic heart disease using the AREC system. Ann Thorac Surg. 1997;63:1298-302. https://doi.org/10.1016/S0003-4975(97)00253-1

3. Black MD, Coles JG, Williams WG, Rebeyka IM, Trusler $\mathrm{GA}$, Bohn D et al. Determinants of success in pediatric cardiac patients undergoing extracorporeal membrane oxygenation. Ann Thorac Surg. 1995;60:133-8. https://doi.org/10.1016/S0003-4975(95)00238-3

4. Walters HL, Hakimi M, Rice MD, Lyons JM, Whittlesey GC, Klein MD, et al. Pediatric cardiac surgical ECMO: multivariate analysis of risk factors for hospital death. Ann Thorac Surg 1995;60:329-37. https://doi.org/10.1016/0003-4975(95)00410-M

5. Merkle J, Azizov F, Sabashnikov A, Weixler V, Weber C, 
N. S. Erese ve ark., Pediyatrik Kardiyak Cerrahi Sonrası Ekstrakorporeal Membran Oksijenasyonu Uygulanan Hastalarda Organ Disfonksiyonu ve Mortalite İlişkisi

Djordjevic I et al. Pediatric patients requiring extracorporeal membrane oxygenation in heart failure: 30-day outcomes; mid- and long-term survival. A single center experience. Artif Organs. 2019 Oct; 43(10):966-75. https://doi.org/10.1111/aor.13501

6. Luo XJ, Wang W, Hu SS, Sun HS, Gao HW, Long C, et al. Extracorporeal membrane oxygenation for treatment of cardiac failure in adult patients. Interact Cardiovasc Thorac Surg. 2009;9(2):296-300. https://doi.org/10.1510/icvts.2008.197681

7. Rastan AJ, Lachmann N, Walther T, Doll N, Gradistanac $\mathrm{T}$, Gommert JF, et al. Autopsy findings in patients on postcardiotomy extracorporeal membrane oxygenation (ECMO).Int J Artif Organs. 2006 Dec;29(12):112131. https://doi.org/10.1177/039139880602901205

8. Rastan AJ, Dege A, Mohr M, Doll N, Falk V, Walther T, et al. Early and late outcomes of 517 consecutive adult patients treated with extracorporeal membrane oxygenation for refractory postcardiotomy cardiogenic shock.J Thorac Cardiovasc Surg. 2010 Feb;139(2):30211, 311.e1. https://doi.org/10.1016/j.jtcvs.2009.10.043

9. Combes A, Leprince P, Luyt CE, Bonnet N, Trouillet JL, Léger $P$, et al. Postcardiotomy mechanical support: risk factors and outcomes. Crit Care Med. 2008 May; 36(5):1404-11. https://doi.org/10.1097/CCM.0b013e31816f7cf7

10. Elsharkawy HA, Li L, Esa WA, Sessler DI, Bashour CA. Outcome in patients who require venoarterial extracorporeal membrane oxygenation support after cardiac surgery. CA J Cardiothorac Vasc Anesth. 2010 Dec; 24(6):946-51. https://doi.org/10.1053/j.jvca.2010.03.020

11. Smith $M$, Vukomanovic A, Brodie $D$, Thiagarajan $R$, Rycus $\mathrm{P}$, Buscher $\mathrm{H}$. Duration of veno-arterial extracorporeal life support (VA ECMO) and outcome: an analysis of the Extracorporeal Life Support Organization (ELSO) Registry Crit Care. 2017;6;21(1):45. https://doi.org/10.1186/s13054-017-1633-1

12. Ayık M F, Işık O, Akyüz M, Atay Y. Pediyatrik kalp cerrahisinde ekstrakorporeal membran oksijenasyonu kullanımı. Ege Tıp Dergisi. 2014;53(3):173-176173 https://doi.org/10.19161/etd.344081

13. Dohain AM, Abdelmohsen G, Elassal AA, El Mahrouk $A F, A l-R a d i$ OO. Factors affecting the outcome of extracorporeal membrane oxygenation following paediatric cardiac surgery. Cardiol Young 2019 Dec; 29(12): 1501-9. https://doi.org/10.1017/S1047951119002634

14. Merrill ED, Schoeneber L, Sandesara P, Molitor-Kirsch E, O'Brien JR J, Dai H, et al. Outcomes after prolonged extracorporeal membrane oxygenation support in children with cardiac disease-Extracorporeal Life Support Organization registry study. J Thorac Cardiovasc Surg 2014 Aug; 148(2):582-8.

https://doi.org/10.1016/j.jtcvs.2013.09.038

15. Black MD, Coles JG, Williams WG, Rebeyka IM, Trusler
GA, Bohn D, et al. Determinants of success in pediatric cardiac patients undergoing extracorporeal membrane oxygenation in children after cardiac surgery. Ann Thorac Surg. 1995;60:133-8. https://doi.org/10.1016/S0003-4975(95)00238-3

16. Mariscalco G., Cottini M., Dominici C., Banach M, Piffaretti $G$, Borsani $P$, et al. The effect of timing of cardiac catheterization on acute kidney injury after cardiac surgery is influenced by the type of operation. International Journal of Cardiology. 2014;173(1):4654. https://doi.org/10.1016/j.ijcard.2014.02.010

17. Smith AH, Hardison DC, Worden CR, Fleming GM, Taylor MB. Acute renal failure during extracorporeal support in the pediatric cardiac patients. ASAIO Journal. 2009 Jul; 55(4):412-6. https://doi.org/10.1097/MAT.0b013e31819ca3d0

18. Cheng R, Hachamovitch R, Kittleson M, Patel J, Arabia $\mathrm{F}$, Moriguchi J, et al. Complications of extracorporeal membrane oxygenation for treatment of cardiogenic shock and cardiac arrest: a meta-analysis of 1,866 adult patients. Ann Thorac Surg. 2014 Feb; 97(2):610-6. https://doi.org/10.1016/j.athoracsur.2013.09.008

19. Lin CY, Tsai FC, Tian YC, Jenq CC, Chen YC, Fang JT, et al. Evaluation of outcome scoring systems for patients on extracorporeal membrane oxygenation. Ann Thorac Surg. 2007 Oct; 84(4):1256-62. https://doi.org/10.1016/j.athoracsur.2007.05.045

20. Kilburn DJ, Shekar K, Fraser JF. The complex relationship of extracorporeal membrane oxygenation and acute kidney injury: causation or association? Biomed Res Int. 2016;2016:1094296. https://doi.org/10.1155/2016/1094296

21. Ballmer PE. Causes and mechanisms of hypoalbuminemia. Clin Nutr. 2001;20:271-3. https://doi.org/10.1054/clnu.2001.0439

22. Haller C. Hypoalbuminemia in renal failure. pathogenesis and therapeutic considerations. Kidney Blood Press Res. 2005;28:307-10. https://doi.org/10.1159/000090185

23. Jellinge $M E$, Henriksen DP, Hallas $P$, Brabrand $M$. Hypoalbuminemia is a strong predictor of 30-day allcause mortality in acutely admitted medical patients: A prospective, observational, cohort study. PLoS One. 2014;9(8):e105983. https://doi.org/10.1371/journal.pone.0105983

24. Brienza N, Dalfino L, Cinnella G, Diele C, Bruno F, Fiore T. Jaundice in critical illness: promoting factors of a concealed reality. Intensive Care Med. 2006;32(2):26774. https://doi.org/10.1007/s00134-005-0023-3

25. Leite HP, Fisberg $M$, de Carvalho WB, de Camargo Carvalho AC. Serum albumin and clinical outcome in pediatric cardiac surgery. Nutrition 2005 May; 21(5):553-8. https://doi.org/10.1016/j.nut.2004.08.026

26. Nikolaou M, Parissis J, Yilmaz MB, Seronde MF, Kivikko 
$\mathrm{M}$, Laribi S, et al. Liver function abnormalities, clinical profile, and outcome in acute decompensated heart failure. Eur Heart J. 2013;34(10):742-9.

https://doi.org/10.1093/eurheartj/ehs332

27. Thomson SJ, Cowan ML, Johnston I, Musa S, Grounds $M$, Rahman TM. Liver function testson the intensive care unit: a prospective, observational study. Intensive Care Med. 2009;35(8):1406-11. https://doi.org/10.1007/s00134-009-1511-7

28. Roth C, Schrutka L, Binder C, Kriechbaumer L, Heinz G, Lang IM , et al. Liver function predicts survival in patients undergoing extracorporeal membrane oxygenation following cardiovascular surgery. Crit Care. 2016; 20:57. https://doi.org/10.1186/s13054-016-1242-4

29. Kaestner F, Rapp D, Trudzinski FC, Olewczynska N, Wagenpfeil $S$, Langer $F$, et al. High serum bilirubin levels, NT-pro-BNP, and lactate predict mortality in long-term, severely III respiratory extracorporeal membrane oxygenation patients. ASAIO J. Mar/Apr 2018;64(2):232-7. https://doi.org/10.1097/MAT.0000000000000610

30. Murphy DA, Hockings LE, Andrews RK, Aubron C,
Gardiner EE, Pellegrino VA, et al. Extracorporeal Membrane Oxygenation-Hemostatic Complications. Transfus Med Rev 2015 Apr; 29(2):90-101.

https://doi.org/10.1016/j.tmrv.2014.12.001

31. Williamson DR, Albert M, Heels-Ansdell D, Arnold DM, Lauzier F, Zarychanski R, et al. Thrombocytopenia in critically ill patients receiving thromboprophylaxis: frequency, risk factors, and outcomes. Chest 2013;144:1207-15.

https://doi.org/10.1378/chest.13-0121

32. Gupta P, Robertson MJ, Rettiganti M, Seib PM, Wernovsky G, Markovitz B, et al. Impact of timing of ECMO initiation on outcomes after pediatric heart surgery: A multi-institutional analysis. Pediatr Cardiol 2016;37:971-8.

https://doi.org/10.1007/s00246-016-1379-6

33. Alsoufi B, Awan A, Manlhiot C, Al-Halees Z, Al-Ahmadi $M, M c C r i n d l e ~ B W$, et al. Does single ventricle physiology affect survival of children requiring extracorporeal membrane oxygenation support following cardiac surgery? World J Pediatr Congenit Heart Surg. 2014 Jan 1; 5(1):7-15.

https://doi.org/10.1177/2150135113507292 